\title{
Doing a Doctorate in BISE in Germany, Austria and Switzerland? A Debate on the Why, What and How
}

\author{
Jan Marco Leimeister · Jörg Becker • \\ Armin Heinzl $\cdot$ Robert Winter • David Gefen
}

Published online: 16 October 2019

(c) Springer Fachmedien Wiesbaden GmbH, ein Teil von Springer Nature 2019

\section{Introduction}

In recent years, the doctorate degree has been subject to a seeming loss of value (e.g., Cyranoski et al. 2011; Economist 2010; Guldner 2019). One striking indicator is the decline in number of top executives with doctorates: while $58 \%$ of board members of German companies held a doctorate in 2007, this number has shrunk to $44 \%$ in 2017 (Guldner 2019). Other indicators of labor market success

Prof. Dr. J. M. Leimeister ( $\square)$

Institute of Information Management, University of St. Gallen, Müller-Friedberg-Strasse 8, 9000 St. Gallen, Switzerland

e-mail: janmarco.leimeister@unisg.ch

Prof. Dr. J. M. Leimeister

Research Center for IS Design (ITeG), Information Systems, University of Kassel, Pfannkuchstraße 1, 34121 Kassel,

Germany

Prof. Dr. Dr. h.c.mult. J. Becker

Lehrstuhl für Wirtschaftsinformatik und

Informationsmanagement, Universität Münster, 48149 Münster, Germany

e-mail: becker@ercis.uni-muenster.de

Prof. Dr. A. Heinzl

Chair of General Management and Information Systems, University of Mannheim, 68161 Mannheim, Germany

e-mail: heinzl@uni-mannheim.de

Prof. Dr. R. Winter

Institut für Wirtschaftsinformatik, Universität St. Gallen (HSG), 9000 St. Gallen, Switzerland

e-mail: robert.winter@unisg.ch

Prof. D. Gefen

LeBow College of Business, Drexel University, Philadelphia,

USA

e-mail: gefend@drexel.edu have also deteriorated for doctorate holders over the last 20 years: incomes have fallen and fewer doctorate holders than before are working full-time - at a time when the labor market has otherwise developed well (e.g., Economist 2010). Yet, the need for highly qualified employees for example with respect to digitization has been growing. Just recently, for example, companies' demand for experts on Artificial Intelligence (AI) has seen a stark increase (Fasse and Kerkmann 2018). This makes it all the more surprising that the growing number of doctoral students (an average growth of $44 \%$ over the last 20 years) has not been enthusiastically received by the labor market and may imply that the doctorate has degenerated into a meritorious commodity. This development may also increasingly affect the Business and Information Systems Engineering (BISE) community and, therefore, requires a discourse on the role of the doctorate in our field, including companies (demandside) and universities (supply-side). How can we make sense of these trends? Traditionally, receiving a doctorate has been commonplace in German-speaking areas (as well as in Scandinavia), and more so than in other areas. The reason for this is that it has been regarded as an instrument for educating and forming social, economic and political elites. These countries have a free university system, but no elite institutions as for example France, the United Kingdom or the United States of America (Preston 2014). Hence, the doctorate also adopts the role of signaling excellence, which in other cultural areas happens on an institutional level. Despite the negative trends mentioned above, this "signifier effect" has been preserved in some areas: in natural sciences such as biology or chemistry, but also within business administration especially with respect to professional service firms (Guldner 2019). However, obtaining a doctorate no longer represents the only viable option for young people to stand out from the crowd, since 
many alternatives are now available to them, be it a stay abroad, an MBA degree, or a visit to the start-up scene.

This raises the question as to whether one can proceed from a special culture in these countries or whether one should explicitly play a different role, for example analogous to the Anglo-Saxon system only with doctorates that essentially prepare for an academic career? This change of course deprives a university of the important network of professionally successful alumni. Moreover, this may further strain the problem of an overcrowded academic labor market (Cyranoski et al. 2011; Sauermann and Roach 2016). However, it could bring an institution, if it is strong in international research, on par with the doctoral education of elite Anglo-Saxon universities. Otherwise and if one remains with the current system, the question naturally arises of what universities must do and offer in order to get the best candidates for these doctorates and, accordingly, also train them for high level positions in business - a question very relevant to the BISE community as a provider of potential executives with capabilities needed in managing digitally enabled organizations. In this regard, I especially see the following challenges for doctoral education in our field:

- Relevance Versus Rigor In the past years, we have experienced a push towards more rigor in BISE research, often at the expense of relevance. This has important implications for the business and societal value of the doctorate. It is true that more researchers from the DACH region successfully publish in basket journals. On the other hand, research today often comes in the form of high-level theoretical insights that are often outdated at the time of publishing and, therefore, only bear little relevance to contemporary business practice. Moreover, the lengthy - often years-long and tedious process of working on refining an article does not support doctoral students in acquiring those skills needed for a career in the fast-paced world of business or support a quick transition into practice [the average doctorate in 2017 took 4 years in comparison to 2 years half a century ago (DZHW 2014; Preston 2014)].

- Company-Versus University-Based The environment in which we as BISE scholars perform research has undergone a dramatic transformation. One of the fundamental changes concerns the availability of information - we have moved from a world where information was scarce towards one where information is largely freely available and access is not hindered by organizational boundaries (De Meyer 2013). Traditionally, universities, with their oligopoly on information, were the best place to perform research and to train knowledge-workers and experts. Today, knowledge generation is increasingly pluralistic with players such as think tanks, policy institutes and companies especially so in BISE. In some fields, like for example AI, universities are already lagging far behind their counterparts in practice. They represent no longer the foremost engine of knowledge generation. Thus, the "expertise" of doctorates is often outdated or too specific when they enter the labor market.

- Interdisciplinary Versus Disciplinary A final issue concerns the nature of our work: writing reports on experiments, giving academic presentations and conducting in-depth 6 months literature reviews is not useful nor sufficient in a world where knowledge needs to be understood quickly and explained in simple terms to larger audiences. In this regard, we may have reached marginal, declining returns on disciplinary research (still the modus operandi in our field) (Eymann et al. 2014). The interesting research problems, namely those that address societies' "wicked problems", require multidisciplinary approaches, i.e., where solutions come from a combination of different disciplines. Most notably, digitization increasingly challenges disciplinary boundaries and, therefore, raises the need for highly qualified specialists for cross-solution and crossdisciplinary issues ("T-Shape"). Thus it is, therefore, surprising that there are still few doctoral students in BISE working in multi-disciplinary teams.

What are the lessons we might want to learn from the contributions of practitioners (demand-side) and distinguished academics (supply-side) in our field? Many associated with BISE are concerned about the current state of the doctorate. While some seem to cope with current challenges, others quarrel with them. It is of utmost importance for universities, businesses and society to find answers to the questions of why and how to do a doctorate in BISE? Against this background, we hope that the debaters' positions contribute to an inspiring discourse on the future of the doctorate in our discipline.

Jan Marco Leimeister

\section{What does Practice Think? Who Hires our Doctorates and Why?}

According to the industry partners I have spoken to in the course of organizing this discussion section, doctoral graduates are still interesting prospective candidates for a wide range of positions in organizations. Both, corporations as well as professional service firms, value doctoral graduates for their ability to conceptualize new and complex topics, their ability to independently drive a project forward, and their specialist knowledge. Therefore, they 
regularly employ doctoral graduates for positions with a strategic focus such as assistants to the executive board or as management consultants as stated by Andreas Maier, CIO of AXA Switzerland, and Dr. Sebastian Klapdor, Partner at McKinsey \& Company:

- Andreas Maier, CIO of AXA Versicherungen AG "For me, above all, the continual strategy development process is an important and suitable field of activity for prospective doctoral graduates in our organization. Although I could also approach classic management consultancies for this kind of task, I see a more sustainable path in hiring the best strategic talents with strong conceptual and structural skills. Therefore, I have chosen to regularly recruit top-educated doctoral students from the best institutions in the field of BISE as assistants to the executive board. They have a strong conceptual skillset coupled with the ability to abstract from the concrete problem and to independently drive a project forward. Moreover, they are accustomed to anticipating strategic developments, familiarizing themselves with new complex topics, structuring them, and packaging them with business knowledge so that they can be discussed in a 'board-compatible' way. After 2 or 3 years, these talents are usually ready to take the next developmental step in a large company like ours, typically in the fields of corporate development, leadership, strategic transformation and change. For many years, I was able to accompany some of these doctoral graduates and each of them found an extremely exciting careers in a large, international company".

- Dr. Sebastian Klapdor, Partner at McKinsey \& Company "Applicants with a doctorate are interesting for us, because they have learned to deal with complex tasks in depth. In addition, they often have a great deal of specialist knowledge in individual specialist areas, which in particular our clients greatly appreciate. This is why our fellowship program offers our colleagues the opportunity to take a break after 2 years for another academic degree such as a doctorate or MBA. The doctorate is very popular with our consultants: about $70 \%$ decide on a doctorate during their time off."

\section{Jörg Becker, Full Professor and Chair for Information Systems at the University of Münster, Germany}

A doctorate in the BISE domain is still a unique career path, which opens many doors in research as well as in industry. However, to achieve this in today's society, the doctorate should be interdisciplinary and have a clear practical relevance.

Doing a doctorate in BISE is a promising career decision, as it presents the unique opportunity to focus on a specific and innovative topic for a longer period. Additionally, it shows how one is able to address a relevant topic in a structured and methodologically sound way. Third, especially in the BISE-domain, the doctoral student has the chance to advance the world we live in through innovative technological solutions. These solutions often have a viral effect due to their technological basis, which is easily accessible all over the world. Nearly all innovations that disrupt today's business are either based on IT, somehow driven by it or at least supported by it. Therefore, the active choice towards a doctorate in the BISE-domain is the best decision a prospective young researcher can make. One might argue that these technological skills could just as well, or even better, be acquired in a start-up or technologically oriented company. While it might be true that one can acquire similar skills in practice, a $\mathrm{PhD}$ candidate will additionally extend the existing body of knowledge in their domain in a structured way, which most industry involvements do not support.

However, a good mixture of university-based and industry-based research can be the key to success in training doctoral candidates. In the first job interview after having received their doctorate, frequently the question is raised whether he or she has "real" work experience and how the time at the university prepared him or her for an industry career. A close connection to industry (e.g., through joint research projects) helps to ensure the relevance of their research as well as preparing them for their time after the $\mathrm{PhD}$ - possibly outside of the theoretical world of the university. The necessary theoretical rigor is a prerequisite for earning the doctorate degree. It is taught throughout the $\mathrm{PhD}$ program and indirectly enforced through the publication system of our top conferences and journals.

Addressing the issue of disciplinary versus interdisciplinary research, I agree that many research domains focus too much on themselves and do not look beyond the horizon. From my point of view, BISE is in its very nature an interdisciplinary research field. The IT systems that we design, build, or investigate are always related to a human who controls or is influenced by them. Therefore, I agree with the statement that more doctoral students should work in multi-disciplinary teams and projects, but I do not think that it is a major problem in our domain. Some good examples of interdisciplinary collaborations within our field are, e.g., BISE with psychology (Ellwart et al. 2019) or BISE with mathematics, statistics, and the media industry (Becker et al. 2019). 
A central skill a PhD candidate should acquire resp. improve is the ability to structure. This is a central objective of my doctoral program (Bergener et al. 2019) and something that any BISE PhD candidate will improve during his doctorate. Problems and challenges are multifacetted and are often encountered in unexpected situations. The ability to structure a problem and design a structured and methodologically sound solution approach is the key to success (in research as in practice).

Another aspect that I try to get my doctoral candidates acquainted with is the ability to quickly become familiar with new - so far unacquainted - topics and assignments. It is my belief that, even though a doctoral thesis means to focus on one topic and become an expert in a very specific domain, it is just as important to have a wide portfolio of skills and be able to adapt quickly.

Our doctoral program at the University of Münster recently received a major update. The examination regulation specifies that every $\mathrm{PhD}$ candidate acquires five certificates on a variety of academic as well as methodological topics. These can be earned through seminars, doctoral consortiums, or selected conferences. My chair of Information Management and Information Systems at the University of Münster "produces" around four to five PhDs per year and our department of "Wirtschaftsinformatik" more than ten PhDs per year. As outlined above, my goal is to train the candidates for a variety of "markets", positions and challenges. Therefore, nearly any employee with any kind of background can become a $\mathrm{PhD}$ candidate at my chair. However, a personality trait which I specifically value is the ability to work independently.

Recent focus topics at my chair have been process modelling, data management, retail and ERP systems as well as e-government. My recent graduates ended up in different positions, ranging from innovative start-ups over consulting firms to established firms from different domains. About twenty of them now work as professors in universities or universities of applied sciences (about equally divided). This shows that there is no contradiction between training them for work in industry or in academia.

There are many relevant research streams within BISE which will persist and still be relevant in 10 or more years. With respect to the business process management (BPM) department, I expect the domain to stay true to its roots as well as address promising new topics. We discussed some of them in the recent BISE anniversary article "Views on the Past, Present, and Future of Business and Information Systems Engineering" (van der Aalst et al. 2018), such as Industry 4.0, Internet of Things (IoT), Blockchain, Data Science and Data Analytics, as well as Sematic Process Modelling Languages, Process Mining, and using AI techniques.
In a nutshell, I believe that the environment of BISE doctorates and the doctorates themselves have undergone many changes and will continue to do so, but they have neither lost in relevance nor value.

\section{Armin Heinzl, Full Professor and Chair for Information Systems at University of Mannheim, Germany}

The reasons "why" for a doctorate are multi-faceted. It is a unique lifetime decision for individuals who are passionate to work on an exceptional project for creating new knowledge. In other words: it is the decision to innovate and to feed back the results to reality. In the age of digital innovation, this has become a key capability for every professional, manager, and academic. Thus, a doctorate combines relevance and rigor, delineating our discipline as a real science. Digital innovation involves (1) identifying significant unsolved problems, (2) deriving a research problem and decomposing it, (3) deploying rigorous research methods for problem-solving, (4) offering a theoretical or technological contribution to our field, and (5) ingraining the contribution into reality.

The University of Mannheim offers two trajectories for "how" to pursue a doctorate: (1) as a research assistant with a moderate portion of graduate courses and a salary; or (2) as a doctoral student in the Center of Doctoral Studies in Business (CDSB) on the basis of a scholarship (https://gess.uni-mannheim.de/doctoral-programs/businesscdsb.html). The CDSB was established through the German Excellence Initiative.

Is the traditional research assistant model geared towards relevance and industry while the CDSB model targets rigor and academia? No - not at all! Both models compete against each other but are permeable. Students that prefer a structured learning environment opt into the CDSB model. Candidates who want to enjoy academic freedom prefer the research assistantship. Both models encourage multidisciplinary work. We admit psychologists, engineers, computer scientists and other backgrounds in both models. The CDSB integrates valuable content and methods from economics, the social sciences, psychology, and computer science. But courses are also open for research assistants. If a doctoral student intends to ingrain field work, she/he can do so under both trajectories. Industry projects focus on practical problems and offer funds for financing research. They can be integrated into the CDSB model after 1.5 years, freeing up scholarships for the next generation of doctoral students. Anything goes and the structures are permeable!

The "what?" is similar for both trajectories and must be developed by the doctoral student. It should not be merely 
a functional or rational research question. It should be ingrained by her/his passion and self-interest. Sense-making may be induced by social, economic, or technological problems. It is propelled by multi-disciplinary and personal inclination and disposition. Some doctoral students prefer theorizing, modeling and empirical testing, while others prefer designing, implementing and evaluating technological artifacts. There is nothing more practical than a good theory ${ }^{1}$ and there is nothing more instrumental than a good technology. Anything goes! Doctoral students should follow their aspirations and desires. Our mission is to direct them towards the future and reality.

Under both trajectories, the doctoral student's theme and method desires must fit the capabilities and interests of the prospective research environment. The "fit" is highly important since knowledge creation is an iterative, yet recursive process that requires the support of experienced researchers. Although the degree will be an individual achievement, knowledge generation follows a team-based logic where socialization, knowledge externalization and knowledge recombination play decisive roles (Nonaka and Takeuchi 1995). Therefore doctoral students should reach out to experienced researchers and integrate into their environments. The advisors will guide the doctoral student and determine whether the "what" and the "how" in the research proposal are promising and substantial. "Integrating" also includes building strong relationships with the advising professors, other doctoral students, and industry or societal stakeholders. This includes presenting one's own research at international conferences and in the field, and, presumably, conducting research visits in other institutions and in organizations. The ultimate plan is to document research results in renowned outlets and to feed back the new knowledge to the field. Developing new knowledge is anything but trivial and the process imposes many impediments. Hopefully, the outcomes are pioneering, and the environment is enjoyable (Heinzl 2008).

Which model is better? A research assistantship is less formalized, offers less course work and provides more capacity for field work. It follows the traditional model in Europe's German speaking countries and beyond. But it requires the student to be more proactive in studying and acquiring method skills. The doctoral program follows the Anglo-Saxon tradition and infuses instrumental knowledge through courses during the first three semesters.

Is there a clear recommendation? - No, there isn't. Young scholars should follow their aspirations and desires. The world is too fascinating and too complex to predetermine strategic choices. The decision towards one approach

\footnotetext{
${ }^{1}$ Many sources attribute this citation to Kurt Lewin. However, there is evidence that it is from Immanuel Kant or Ludwig Boltzmann. See Billig (2015) or Wikiquote (2019) for details.
}

should be ingrained in the doctoral students' passion and motivation for relevance and rigor, industry and university, as well as disciplinary and multi-disciplinary work. The doctoral degree will ultimately be the same. Our dual approach helps us to attract global talent and to improve our quality. All stakeholders involved will be better prepared for the future. ${ }^{2}$

\section{Robert Winter, Full Professor and Director at University of St. Gallen, Switzerland}

Having supervised over $60 \mathrm{PhD}$ students in my career and having served as an Academic Director of a 450 student strong PhD program (in Management) for 6 years, I am convinced that a $\mathrm{PhD}$ in BISE will even become more attractive for top BISE Master graduates as long as Doctoral education is organized in a flexible and professional way.

In my opinion, the major benefits of a doctorate are intact:

- Most Master graduates are well aware that Doctoral studies will be the last (and sometimes only) chance to immerse in a topic seriously - and widely independently - before starting a consulting or management career.

- In most places, at least in DACH, BeNeLux and the Nordic countries, a BISE PhD is no "path of no return" into academia, but is a highly valued asset in most private and public organizations (so that less than $10 \%$ of our PhD stay in academia even in the long run). E.g., the majority of the St. Gallen BISE PhDs are hired as C-level assistants or senior consultants ( $\mathrm{PhD}$ is credited towards professional experience), fast-tracking them to general management, CTO, project management or engagement management roles.

- BISE PhDs are a unique opportunity for gaining research credentials in an increasingly VUCA world: DBAs are (rightfully) perceived as less challenging (applying research rather than doing genuine research), MBAs are mostly redundant for BISE graduates, and on-the-job education may be research-related, but clearly lacks status recognition.

However, several developments challenge the BISE $\mathrm{PhD}$ success story. Some universities morph their Doctoral education into tightly (and centrally) organized programs with pure academic focus, some companies aim to integrate universities into their on-the-job talent development programs, some polytechnics strive to award $\mathrm{PhD}$ titles

\footnotetext{
${ }^{2}$ Many thanks go to Monica Fallon, University of Mannheim, who mirrored my thoughts and perfectioned my statement.
} 
(instead of more appropriate DBA titles) for research-oriented practice projects, and some international educational institutions offer distance $\mathrm{PhD}$ programs.

University brand value, research standing and a broad graduate base alone, however, do not secure a successful Doctoral education in an increasingly dynamic and varied educational and economic environment. In the case of St. Gallen, we had to fundamentally overhaul Doctoral studies twice during the last 15 years. The major changes were centered around managing flexibility and diversity, as well as increasing transparency and professionalism. We believe that universities and professors should work towards establishing certain prerequisites:

- $\mathrm{PhD}$ projects should follow a professional and dependable development process. Assurance of learning needs to be institutionalized and personal involvement (of both the PhD student and their supervisors) needs to be based on transparency and professionalism - such as following a reference process, having regular feedback talks and establishing dual control.

- Research methods and state-of-the art theory knowledge on PhD level need to be systematically trained. Larger institutions who are able to develop and maintain offers of their own (such as the Global School in Empirical Research Methods, https://www.gserm.ch/; or the VHB ProDok program, https://vhbonline.org/en/events/thedoctoral-program/) should open their offering to $\mathrm{PhD}$ students from smaller institutions that cannot afford such initiatives - and these smaller institutions should encourage their PhD students to attend.

- A critical mass needs to be maintained not only for effective teaching in early phases of Doctoral education, but also for effective peer discussions in advanced phases.

- Since the research community has become global and interactive, scientific exchange beyond supervision and peer discussion should be incorporated into dissertation projects as early and as often as possible, e.g., by involving external senior researchers in the $\mathrm{PhD}$ committee or by supporting cumulative dissertations where peer researchers are involved in reviewer or editorial roles.

- Purely «academic track» Doctoral programs as well as purely practice-oriented Doctoral programs close doors. To qualify for as many attractive career options as possible, program design should aim at rigorous relevance and relevant rigor, i.e., prepare $\mathrm{PhD}$ candidates for careers not only in academia, but also in research-oriented practice.

We have incorporated these principles in St. Gallen not only by differentiating four concentration areas for our Dr.oec./PhD in Management (Business Innovation, General
Management, Accounting, Marketing), but also by offering a wide range of research method courses - both from internal and external providers. The program follows a clear structure consisting of a pre-proposal phase with focus on method education, a phase focusing on the dissertation proposal, and a post-proposal phase with focus on peer discussion.

A well-organized $\mathrm{PhD}$ program does not replace but support the individual student-supervisor collaboration that we deem essential for successful $\mathrm{PhD}$ research. We therefore intentionally avoid committees dominated by "visitors" and instead complement all phases by personal supervision from experienced researchers, with an external co-supervisor being encouraged but not mandatory. Decentral supervision autonomy is embedded in an environment that provides structure, increases transparency and creates incentives for offering and consuming method education.

For some years, the program was offered in two "Academic track" and "Managerial track" variants that differed regarding the number of compulsory courses. Feedback from $\mathrm{PhD}$ graduates as well as the actually chosen career paths, however, led us to drop this differentiation - and increase both the minimum amount of method courses and the program flexibility - because the best $\mathrm{PhDs}$ appreciated "open doors" instead of being pushed into one or the other direction too early.

In summary, I believe the long-lasting past success and future outlook of a BISE PhD needs to be seen in a geocultural and economic context. In DACH, BeNeLux and the Nordic countries a Doctorate is not only a necessary entry step into an academic career, but also a valued asset in most private and public organizations - and this perception will only change very slowly if at all. With increasing dynamics of industry structures, business models and business technology, a post-Master education that preserves options - instead of paving a one-way path seems to be the better choice. A DBA program or a "Graduiertenkolleg" may be attractive options to those who believe that one can make hardly reversible decisions at an age of 23. For those who want to stay flexible and not only apply other's research in a VUCA world, but instead want to do research themselves, a flexible $\mathrm{PhD}$ program in a professional environment will be the superior option.

\section{David Gefen, Full Professor, Provost Distinguished Research Professor, and Academic Director of the DBA Program at Drexel University, USA}

The industry and academia are changing, and with it so too is the meaning and need for a doctorate in business administration. The rise of the DBA in recent years reflects 
in part the change in the nature of the traditional $\mathrm{PhD}$ in business combined with the at last recognized rising need in the industry of the value of a social sciences' thought toolkit of the kind provided by a DBA. Interestingly, there is quite an overlap in our take on a DBA and that of the other panelists to their doctoral programs. The traditional $\mathrm{PhD}$ in business has become less relevant to industry as it has become a more theory and top-tier journal publicationoriented process, and thus less oriented towards solving practical business needs that, important as they are to business, might repeat existing theory and thus be insufficiently novel for a top-tier journal. Rising to the challenge and addressing the open turf left by that shift in the traditional $\mathrm{PhD}$ in business, a DBA of the kind we confer at Drexel University in the US addresses that need. This kind of a DBA provides a thought toolkit that allows for reading theory critically for what it is and no more - i.e., that theory as taught in the Business school is not a panacea as might have been misunderstood based on an MBA, but rather a good idea that applies sometimes and in some contexts and only provides a partial answer with many problems left unanswered.

The picture is obviously more complex than that as many DBA students treat their degree as a backdoor into academia as a second career, completing the grueling doctorate process in 3 years part-time and retaining their current senior or executive positions, rather than spending 5-7 years in a full-time $\mathrm{PhD}$ program at a very reduced compensation level. It is not at that kind of DBA that this piece is dealing with. The DBA discussed here is a highquality research project that is geared at advising the creation of important policy papers, and that as such should have data and analysis and interpretation of the analysis that are as good as those in a traditional $\mathrm{PhD}$ in business. After all, an organization investing millions of dollars in a project based on such DBA research should be provided reliable and valid data and analysis and interpretation comparable to, or maybe even more demanding than, a toptier academic journal.

That expectation of a DBA highlights the key difference, but equal need for high-quality, between a DBA and a traditional $\mathrm{PhD}$ in business. $\mathrm{A} \mathrm{PhD}$ in business and a DBA are both terminal research degrees in business, but they are not the same. A PhD in business, at least in the USA, is geared towards training academics who seek a career in academia. While some people who seek a DBA do it as an entry into academia, mostly as a clinical (teaching) position, many others do so for advancement in their profession through signaling excellence and social scientists' skills or as a prerequisite to a $\mathrm{C}$-suite position. As such the population who seeks a DBA tends to be much different than those seeking a PhD. DBA applicants are mostly in their 40s and 50s. Another key difference between a PhD in business and a DBA is the type of dissertation: geared at a contribution to theory or to advising a practical policy paper. This entails a different approach to research, making a DBA more interdisciplinary and focused on measurable outcomes to the organization.

An example at Drexel University might clarify that point. In recent years we have been doing much research into the implementation of various kinds of telemedicine IT systems. The contribution we can claim to theory is meager: it is the same set of theories and the equivalent problems as with other kinds of technology adoption, making publishing a paper in a top-tier journal harder, except that these are real problems that involve millions of dollars and could affect healthcare quality and quantity. Moreover, as a DBA type research, we can provide systemand context-specific numeric recommendations as to the relative effects of each predictor, moderator, and mediator. And, crucially, while the timeline to making the results public might be 2-3 year at least in the case of a top-tier publication, a DBA study can be applied shortly after the results are available. A typical example of such DBA conclusions that could be of crucial importance to an organization, a medical center in this case, but would be "uninteresting" to a top-tier journal is the effect over time of a new policy that tries to increase the participation of minorities. That men and women, or people from different cultural backgrounds, sometimes perceive the value of and then adopt an IT differently, and that accordingly maybe their training should reflect these differences, is a matter well studied and nothing new from a $\mathrm{PhD}$ research perspective. But, that a specific policy that encouraged women, or people of lesser socio-economic standing, to use the telemedicine IT and how successful it was in numeric terms relative to the adoption rates overtime prior to that policy could be of vital importance to DBA research and to the organization that sponsored the study.

The key issue is that a PhD dissertation in the US system is supposed to create new theory. Arguably, theory is important only to the extent that someone does something with it. And that is where the DBA comes in. A DBA might as a byproduct also create new theoretical understanding, but, as envisioned, a DBA is about taking theoretical understanding, such as that created by $\mathrm{PhD}$ research, and actually applying it to real-world business situations to test, modify, and verify its value, by people who the industry perceive as being "like me". As Cervantes put it in The History of Don Quixote: "The proof of the pudding is in the eating." The PhD dissertation proverbially creates the pudding, the DBA dissertation proverbially shows the value of "eating" it in applying the theory to a practical real-world setting.

In this manner, rigorous DBA programs could be the answer to current challenges sometimes leveraged against 
business PhD research that it has become too "academic" and disconnected from what the industry needs (Galletta et al. 2019). Going back to the research on telemedicine implementation that some of our DBA students are doing, when we present that research to the managers of other medical centers, they are interested. They tell us: I know that medical center, their issues are not exactly those we have, but we can learn from them. That is what business research used to be about. To paraphrase President Lincoln, this kind of research is of the industry, by the industry, for the industry. That is why the industry trusts it.

\section{References}

Becker J, Trautmann H, Grimme C, Brunk J, Niemann M, Assenmacher D (2019) Reduzierung des Moderationsaufwands von Nutzer-Kommentaren mit Hilfe von Automatisierung durch textanalytische Methoden. https://www.uni-muenster.de/for schungaz/project/12394?lang=en. Accessed 14 July 2019

Bergener K, Räckers M, Stein A (2019) The art of structuring bridging the gap between information systems research and practice, 1st edn. Springer, Heidelbert

Billig M (2015) The myth of Kurt Lewin and the rhetoric of collective memory in social psychology textbooks. Theory Psychol 25(6):703-718

Cyranoski D, Gilbert N, Ledford H, Nayar A, Yahia M (2011) Education: the PhD factory. Nature 472(7343):276-279

De Meyer A (2013) The future of doctoral education in business administration. J Manag Dev 32(5):477-486

DZHW (2014) Karrieren Promovierter - Wirtschaftswissenschaften. https://www.dzhw.eu/pdf/22/ergebnisse_wirtschaftswissenschaf ten_promoviertenstudie.pdf. Accessed 19 September 2019

Economist (2010) Why doing a PhD is often a waste of time: the disposable academic. The economist. https://medium.economist. com/why-doing-a-phd-is-often-a-waste-of-time-349206f9addb. Accessed 19 September 2019

Ellwart T, Ulfert AS, Antoni Conny H, Becker J, Frings C, Göbel K, Hertel G, Kluge A, Meeßen SM, Niessen C, Nohe C, Riehle Dennis M, Runge Y, Schmid U, Schüffler A, Siebers M, Sonnentag S, Tempel T, Thielsch MT, Wehrt W (2019)
Intentional forgetting in socio-digital work systems: system characteristics and user-related psychological consequences on emotion, cognition, and behavior. AIS Trans Enterp Syst 4:1-19

Eymann T, Kundisch D, Wehrmann A, Legner C, Schell A, Weitzel T (2014) Are requirements for graduates of master and $\mathrm{PhD}$ programs in business and information systems engineering changing? Bus Inf Syst Eng 6(6):367-376

Fasse M, Kerkmann C (2018) Autokonzerne suchen händeringend Experten für Künstliche Intelligenz. Handelsblatt. https://www. handelsblatt.com/unternehmen/industrie/digitaler-jobmarkt-auto konzerne-suchen-haenderingend-experten-fuer-kuenstliche-intel ligenz/20982406.html?ticket=ST-9475491-LDLfaPSe6yje G7e302Zh-ap6. Accessed 19 September 2019

Galletta DF, Bjørn-Andersen N, Leidner DE, Markus ML, Mclean ER, Straub D, Wetherbe J (2019) If practice makes perfect where do we stand? Commun AIS 44:555-580

Guldner J (2019) Wenn der Doktortitel zum Karrierekiller wird. WirtschaftsWoche. https://www.wiwo.de/my/erfolg/hochschule/ karriere-wenn-der-doktortitel-zum-karrierekiller-wird/24074982. html?ticket=ST-3088872-dHzgghqbdxDhq0KwCWPD-ap2. Accessed 19 September 2019

Heinzl A (2008) Zur Notwendigkeit einer strukturierten Doktorandenausbildung in der Wirtschaftsinformatik. In: Jung R, Myrach T (eds) Quo Vadis Wirtschaftsinformatik? Festschrift für Prof. Gerhard F. Knolmayer zum 60. Geburtstag, Gabler, Wiesbaden, pp 241-264

Nonaka I, Takeuchi H (1995) The knowledge-creating company: how Japanese companies create the dynamics of innovation. Oxford University Press, Oxford

Preston JC (2014) Online doctoral programs: can they produce the business scientists and leaders needed for the 21 st century? Int $\mathrm{J}$ Leadersh Change 2(1):39-47

Sauermann H, Roach M (2016) Why pursue the postdoc path? Science 352(6286):663-664

van der Aalst WMP, Becker J, Bichler M, Buhl HU, Dibbern J, Frank U, Hasenkamp U, Heinzl A, Hinz O, Hui KL, Jarke M, Karagiannis D, Kliewer N, König W, Mendling J, Mertens P, Rossi M, Voss S, Weinhardt C, Winter R, Zdravkovic J (2018) Views on the past, present, and future of business and information systems engineering. Bus Inf Syst Eng 60(6):443-477

Wikiquote (2019) Kurt Lewin - 'Es gibt nichts Praktischeres als eine gute Theorie'. https://de.wikiquote.org/wiki/diskussion:kurt_ lewin. Accessed 14 July 2019 